\title{
Predicting post-deployment family adaptation in U.S. Navy families
}

\author{
Micah A. Scott ${ }^{1 *}$, Esther H. Condon ${ }^{2}$, Arlene J. Montgomery ${ }^{2}$, Spencer R. Baker ${ }^{3}$ \\ ${ }^{1}$ Old Dominion University, School of Nursing, USA \\ ${ }^{2}$ Hampton University, School of Nursing, USA \\ ${ }^{3}$ Hampton University, Department of Counseling, USA \\ *Corresponding author E-mail: mscott@odu.edu
}

\begin{abstract}
Background: Although military families worldwide face changes that include adapting to peace and wartime deployments, few studies have explored how military families adapt to the post-deployment return of a service member.

Objectives: To identify variables that predicted post-deployment adaptation of U.S. Navy families.

Methods: A mixed method study guided by the Roy Adaptation Model included a convenience sample of 142 spouses of service members recently returned from deployment. The degree to which length of deployment, prior deployments, and years married, number of children, participation in religious and family support groups, communication, race, and interdependence predicted post-deployment family adaptation was tested. Multiple regression analysis and content analysis were used to analyze quantitative and qualitative data to better understand post- deployment adaptation of military families.

Results: Post-deployment family adaptation was significantly predicted by having been previously deployed and by scores measuring family interdependence. Content analysis of qualitative responses from 10 spouses indicated that $90 \%$ experienced integrated adaptive responses.

Conclusions: Family interdependence and prior deployments predicted levels of post-deployment family adaptation. Families who "give time" to adjust, communicate, and resume family routines experienced levels of adaptive response.
\end{abstract}

Keywords: Deployment, Family, Family Nursing, Military Families, Spouse.

\section{Background}

Military families across the globe experience frequent deployments. The continued threat of global terrorism has increased the demands placed on military members worldwide and resulted in rapid deployments to war zones, repeated deployments, and delayed returns (St. Laurent, 2004, Adams et al. 2005, Castro \& Adler 2005, Huebner \& Mancini 2008). These factors challenge the ability of families of service men and women to adapt. Although all branches of the military experience separations, few studies, if any, have examined factors that predict adaptation among U.S. Navy families who experienced Operation Enduring Freedom and Operation Iraqi Freedom. For this reason, the current study sought to apply the Roy Adaptation Model (RAM) (Roy 2009) to facilitate an understanding of family readjustment during the reunion period among U.S. Navy families who experienced a deployment during Operation Enduring Freedom and Operation Iraqi Freedom.

Hill's (1949) seminal work established the initial scope of military-related family research with deploying fathers and the challenges they faced upon reunion with their families. That work, contextually broad in scope as it was, narrowed its inquiry to investigating post-deployment social and psychological adjustment of husbands and fathers who were reintegrating into their families. Spouses and children were not a major focus of inquiry other than as supporters of the returning service member. More recent family related research extended the inquiry to family members of deployed service members, women in military service, and children of deployed men and women.

Kelley (1994) examined the effects of military-induced separations on families before and during Operation Desert Shield and Operation Desert Storm (ODS/ODS) and concluded that compared to families in which the military husbands/fathers experienced a peacetime deployment, families who had experienced a wartime deployment had lower levels of post-deployment family cohesiveness. In addition, children's internalizing (e.g., sadness) and externalizing (e.g., aggressiveness) symptomatology showed a steady decline from pre- to post-deployment in families in which fathers experienced a peacetime deployment. These results suggest that wartime deployments may be more stressful and result in more challenges to family adaptation.

Other studies, such as one by Kelly, Herzog-Simmer, and Harris (1994), found that parenting and family functioning were affected by the mother's deployment phase and marital status. Married mothers reported more cohesion and organization than single mothers. There were no other significant main effects noted by these authors, suggesting that within traditional two-parent Navy families, a separation did not reduce the ability of the family to maintain patterns of cohesiveness and organization. Studies of military women are increasingly important as the number of women serving in the military has grown substantially, doubling from $4 \%$ of all veterans in 1990 to $8 \%$ or an estimated 1.8 million in 2011 (U.S. Government Accountability Office 2011). The Veter- 
ans' Administration projects a $17 \%$ increase in female veterans between 2008 and 2033 (U.S. Government Accountability Office 2009).

A study by Medway, Davis, Cafferty, Chappell, and O'Hearn (1995) established the impact of war-related separation on spouses of reservists who were deployed during Desert Storm. The impact of disruption of family life, personal stress, and relational styles of spouses were studied to determine their impact on the psychological responses and behavior of children in the home 6 months after the return of the husband/father. Attachment style of the spouse was found to predict perceived level of stress that in turn predicted the perceived level of disruption of family life. The spouses with attachment styles that were not secure continued to experience levels of stress similar to those experienced during the deployed spouse's absence. The return of normal family function and relationships is likely to be delayed while the behavioral problems of children continue beyond the reunion. The previously described studies addressed child behavior and maternal parenting stress in spouses of pre- and post-deploying service members, thereby extending the scope of inquiry to the spouses of military service members.

Pierce, Vinokur, and Buck (1998) investigated predictors of behavioral and psychological responses of children to the deployment of their mothers who were deployed during the Persian Gulf War serving within either the war zone or outside the war zone. Significant findings indicated that the mother's mental health, difficulty in caring for children prior to and in the two years following deployment, race, age of mothers and children, and gender of children were predictive of psychological and behavioral responses in children. Negative psychological and behavioral responses tended to be transient unless the mother had prior mental health issues, such as depression, or had previous difficulty caring for her children. That study extends family-related research by clarifying the impact of deployment of mothers on the psychological responses and behavior of children. Deployment in and of itself was not predictive of long range negative psychological and behavioral responses in children, but the study points to the role and significance of contextual factors in studying military families.

Peebles-Kleiger and Kleiger (1994) studied the psychological effects of wartime deployment on families following ODS/ODS. Their study of reintegration stress explored wartime deployment as a catastrophic traumatic event for families before and following deployment that created significant stress for families trying to reintegrate a service member who may be experiencing combat related stress, post-traumatic stress disorder, and aggression. These authors reported that families themselves might have been experiencing anger and aggression toward the service member as a result of feelings of abandonment.

These selected studies extended inquiry into military service by the inclusion of spouses of deployed men, deployed women, and children of deployed women who have served in times of war. Continuing global conflict and the likelihood of deployment of military personnel to war zones increases the need for familyrelated research with military families to understand the complex challenges to family function and relationships and to improve services that promote families' adaptation to the demands placed on them during military service.

The current study proposed to test predictors of post-deployment family adaptation as reported by the non-deployed spouses of service members serving in the U.S. Navy during Operation Desert Shield and Operation Desert Storm. The use of an explicit nursing conceptual model to identify and test hypotheses places this study within the growing body of family-related research in nursing by addressing military families.

This study tests the RAM's capacity to explain and predict adaptation of the military family by identifying variables that predict their levels of adaptation at six weeks to 12 months following a 6month deployment. Of particular interest were variables related to communication between the deployed service member and the family during deployment. Methods of communication were of interest because of the range of options now available that were not available in the past in war zones. Early wartime deployments often resulted in lengthy absences with greatly restricted communication that posed delays in the reintegration of the family post deployment. Other important aspects of previous research have shown the importance of the impact of the deployment on families at home. This study integrates these factors to explore the family experience further.

The current study tested a middle range theory of family postdeployment adaptation using RAM (Roy 2009). Roy identified inputs as stimuli that provoke a response. Stimuli can originate from an external environment (external stimulus) or from an internal environment (internal stimulus). It is the individual or family interaction with the environment that creates a response. The environment is defined as being both physical and social and is specifically classified by Roy as providing focal, contextual, or residual stimuli. The combination of certain stimuli creates an internal input that Roy identified as the adaptation level.

The focal stimulus was an internal or external stimulus that immediately confronted the family (Roy \& Andrews 1999). The return of the deployed spouse and parent was the focal stimulus in this study. The contextual stimuli were other internal and external stimuli evident in the situation that influenced a behavior triggered by the focal stimulus. The variables of length of deployment, prior deployments, and years married, number of children, participation in religion, and race were selected as contextual stimuli.

Roy (2009) identified the stabilizer subsystem and the innovator subsystem as coping processes inherent in the functioning of groups. The stabilizer subsystem involves system maintenance, including structure, values, and daily activities to accomplish the purpose of the social system or family (Hanna \& Roy 2001). An example of a stabilizer activity would be communicating on a regular basis with the deployed service member. The stabilizer subsystem variable was communication in this study. The innovator subsystem involves change and growth (Roy \& Andrew 1999). The innovator dynamism involves cognitive and emotional strategies for change to higher levels or potential. Family support groups (FSG) provide families with activities and strategies that may assist family coping from pre-deployment to postdeployment. Therefore, the participation in FSG was designated as a study variable.

The stabilizer and innovator subsystems are manifested in four adaptive modes. Of the four adaptive modes, the interdependence mode was the most applicable to this study. The interdependence mode focuses on close relationships of people as individuals and groups. The central need of the interdependence mode is to maintain relational integrity, which is defined as the feeling of security in a relationship (Roy \& Andrews 1999).

Concepts from RAM were measured as study variables using conceptually appropriate instruments. Study results were interpreted within the context of RAM. The RAM concepts focal and contextual stimuli and the stabilizer and innovator subsystems were the middle range theory concepts that were tested. Fig. 1 shows the conceptual basis for the study.

\section{Materials and methods}

\subsection{Sample}

A total of 142 U.S. Navy spouses completed an online survey to address post-deployment family adaptation. Criteria for the participants were as follows: U.S. Navy spouses with children living in their homes in which the U.S. Navy member had returned within the previous 12 months following 6 months or longer deployment. Data were collected from east and west coast commands over a 4month period in 2008 . Of the 142 participants, 138 were women and 4 were men. Additionally, the first 10 participants answered four optional open-ended questions. 
Conceptual
Framework

Middle Range

Theory Concepts

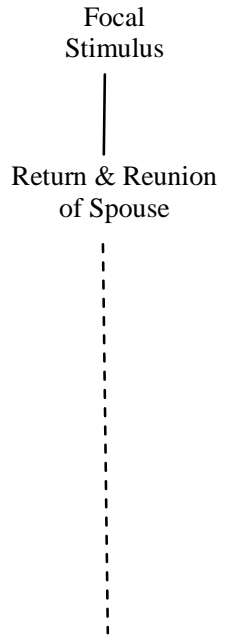

\section{Post Deployment \\ Family Adaptation Demographic \\ Form}

Post Deployment

Family Adaptation Questionnaire

\section{Roy's Adaptation Model}

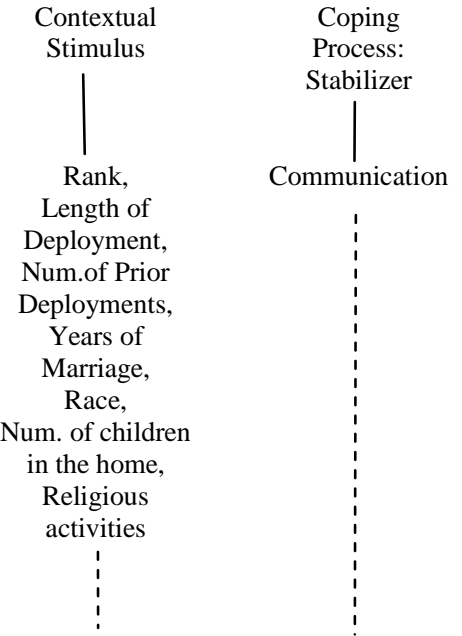

Post Deployment Family Adaptation Demographic Form

\section{Post Deployment Family Adaptation Demographic Form \\ Post Deployment Family Adaptation Questionnaire}
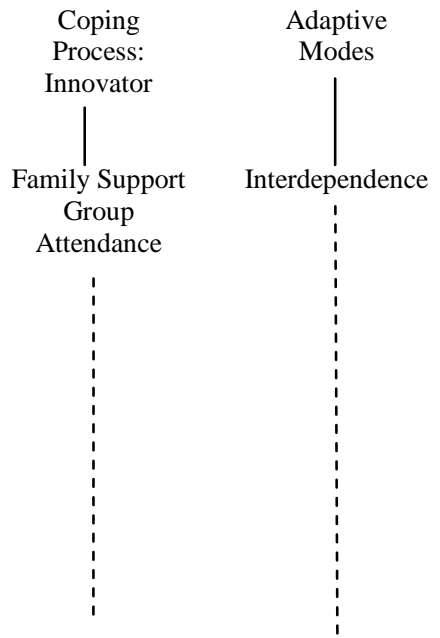

Adaptive Responses

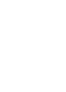

Adaptation Post Deployment
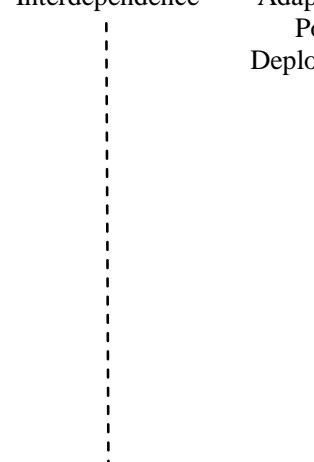

\section{Post Deployment Family Adaptation Demographic Form \\ Post Deployment Family Adaptation Questionnaire}

Family APGAR

Family Adaptation Scale

Post Deployment Family Adaptation Questionnaire

Fig. 1: Conceptual-Theoretical-Empirical Indicators for Post-Deployment Family Adaptation.

\subsection{Procedure}

This was a mixed methods family-related study of U.S. Navy spouses who met the inclusion criteria and consented. They were recruited through links with online survey invitations at Internet sites that military families were likely to visit. Participants were also recruited from ads posted on the daily announcement page for faculty, staff, and students at a large university in southeastern Virginia. A purposeful subsample of 10 participants representing enlisted and officer ranks was used to obtain responses to four qualitative questions. A pilot study was conducted to identify problems with access to the survey Web link, with the study instruments and survey questions.

The pilot study tested the use of the Post-Deployment Family Adaptation Data Form, the Family APGAR (FAPGAR), and the Family Adaptation Scale (FAS) to collect quantitative data. Qualitative data were obtained using the Post-Deployment Family Adaptation Questionnaire developed by the researchers. The pilot study resulted in changes to some questions to enhance clarity and accuracy. Quantitative data from the pilot study were included in the study; however, the qualitative data were not included due to refinements in the instrument.

A researcher-generated Post-Deployment Family Adaptation Data Form obtained data on the variables of rank, race, length of deployment, number of previous deployments, years of marriage, number of children at home, participation in family support groups (FSG) and religious activities, and communication methods. Participants were provided with multiple choices for each survey item. The following codes were used for predictor variables. Rank was coded as $0=$ enlisted personnel and $1=$ officers; length of deployment ranges were $1=6$ to 8 months, $2=9$ to 12 months, 3 $=13$ to 15 months, $4=16$ to 19 months, $5=20$ to 23 months, $6=$ 23 to 25 months, and $7=$ more than 25 months; prior deployments ranges were $0=0,1=1$ to $2,2=3$ to $4,3=5$ to $6,4=7$ to $8,5=$ 9 to $10,6=11$ to $13,7=14$ to $15,8=16$ to $17,9=18$ to 19 , and $10=$ more than 20 ; years or marriage ranges were $1=$ less than 1 years, $2=1$ to 5 years, $3=6$ to 11 years, $4=12$ to 17 years, $5=$
18 to 23 years, and $6=$ more than 24 years; number of children in the home was measured as a continuous variable from 1 to 6 or more; participation in religious activities was coded as $0=$ for less than once per month during the deployment and $1=$ more than once a month during the deployment; communication included emails, letters, phone calls, packages, postcards, cassette tapes, videos, or other was measured as the total sum of communication methods and ranged from 0 to 9; FSGs attended, including meetings, holiday parties, children's events, homecoming meetings, night before homecoming party, and return and reunion meetings, were measured as the total sum and ranged from 0 to 6 .

A second researcher-generated instrument, the Post-Deployment Family Adaptation Questionnaire, was used to acquire qualitative data. Spouses were asked to respond to the following questions:

1) How has the reunion been for you and your family?

2) What type of communication was the most important for you during the deployment, and why was it important?

3) What has helped you adjust to your spouse's return?

4) Now that your spouse has been home, how are things going with you and your family? Please give an example.

Roy's construct of interdependence was measured using the FAPGAR (Smilkstein, Ashworth, \& Montano 1982). According to Roy, interdependence is defined as "the close relationship of people aimed at satisfying needs of affection, development, and resources to achieve relational integrity" (Roy \& Andrews 1999 p.474). Three of the FAPGAR items measured Roy's concepts of interdependence: affection, development, and resources. One question asks, "I am satisfied with the way my family expresses affection and responds to my emotion, such as anger, sorrow, or love." The FAPGAR consists of five items measured on a 5-point scale in which scores are summed to yield a score from 0 to 20 . Scores are summed with higher scores indicating a higher level of family functioning. In previous studies, the FAPGAR had an internal consistency, $\alpha=.86$ (Grotevant $\&$ Carlson 1989) and a twoweek test-retest coefficient of .83 (Sawin, Harrigan, \& Woog 1995). These reliability coefficients suggest that the FAPGAR has been a highly reliable instrument for assessing family functioning (Sawin et al. 1995). Construct validity has also been established 
for the FAPGAR. In the initial development sample, the threeitem choice format was shown to be valid for college students. The three-item version of the FAPGAR increased reliability and item total correlation coefficients. The initial study was followed by a second study that utilized the five-item format (Sawin et al 1995). Researchers recommended that a three-item choice format be retained for clinical use and the five-item format be used for research purposes. Studies with several diverse populations, including families from foreign countries and families experiencing acute and chronic illnesses, indicate that the instrument had levels of acceptable reliability and validity for measuring the family member's satisfaction with the five components of family function (Smilkstein et al. 1982). The five-item format was used for the current study. Cronbach's $\alpha$ was utilized to assess the reliability of the FAPGAR $(\alpha=.81)$ with this sample.

The FAS (Antonovsky \& Sourani 1988) was used to measure family adaptation level by measuring satisfaction with family functioning. Eleven items on the FAS assessed satisfaction within the family and community. Of the 11 items, five items assessed satisfaction within the family. Two of the family satisfaction items referred to family and community relationships; three questions assessed satisfaction within one's family and community. A final question asked respondents to compare their family to an ideally adjusted family. Respondents rated each item using a 7-point scale, ranging from 1 (dissatisfied) to 7 (completely satisfied) Item scores were summed to yield an overall score. According to Antonovsky and Sourani (1988), the scale had a concurrent validity $(r=.68)$ with the Family Sense of Cohesiveness Scale. The FAS has been used with diverse populations including minorities and families with acute and chronic medical conditions and psycholog ical conditions in both in inpatient and outpatient settings (Chamberlain, 2002, McCoy, 2004, Newby 2006). Cronbach's $\alpha$ was utilized to assess the reliability of the FAS $(\alpha=.86)$ with the current study sample.

\subsection{Data analysis}

SurveyMonkey.com allowed the researcher to create anonymous survey responses and collect data that were protected by security systems and in compliance with the regulations of the Health Insurance Portability and Accountability Act of 1996 (HIPAA) (Survey Monkey 2007). Data downloaded from the SurveyMonkey.com site were secured and accessible only to the researcher. Data were downloaded and entered into the Statistical Package for the Social Sciences, version 16, for analysis Only data from completed surveys were analyzed.

Descriptive statistics were used for the first research question in the quantitative component of the study to measure contextual stimuli within the RAM. The frequencies, percentages, means, and standard deviations of the participants' scores were reported. Multiple regression analysis was used to determine if the predictor variables significantly predicted scores on the FAS that measured adaptation.

Qualitative data were obtained with four open-ended questions from the Post-Deployment Family Adaptation Questionnaire. Content analysis of verbatim responses to each question was undertaken to achieve a broad description of family adaptation levels. Analysis proceeded as follows: (a) each response was read; (b) responses were compared for similarities and differences; c) responses were coded according to the RAM adaptation levels; (d) the procedure was repeated with each response to each of the qualitative questions; and (e) a second researcher reviewed the data and analysis for verification (Speziale \& Carpenter 2007). Responses were coded according to RAM adaptation levels for each of the qualitative questions. A second researcher with extensive experience with qualitative research reviewed the data and analysis to verify them. Initially, one researcher interpreted one participant's comments as reflective of a compromised level of adaptation. The second researcher identified the same comments as being a compensatory level of adaptation. The researchers reviewed the participant's score from the FAS. The score was 69 points of a possible 77 and indicative of a high level of adaptation. This places the level between compromised and compensatory. The quantitative data from the FAS supported the qualitative responses as evidence of the stabilizer coping mechanism resulting in a compensatory level of adaptation. Additional comparisons were made between each participant's FAS scores and qualitative responses. Convergence was found between the two.

\section{Results}

In general, the sample included slightly more spouses of officers than enlisted personnel who had been deployed 6 to 8 months and had previous deployments. The majority of the participants were women. In addition, most families had several children, and $89 \%$ of the survey participants were non-minority. Table 1 describes in detail the characteristics of the sample.

Table 1: Descriptive Statistics of the Sample (N=142)

\begin{tabular}{|c|c|c|}
\hline Item & Characteristics & No./\% \\
\hline \multirow[t]{2}{*}{ Rank } & Enlisted & $64(45.1)$ \\
\hline & Officer & $78(54.9)$ \\
\hline \multirow[t]{2}{*}{ Gender } & Women & $138(97.2)$ \\
\hline & Men & $4(2.8)$ \\
\hline \multirow[t]{7}{*}{ Length of deployment } & 6 to 8 months & $119(83.8)$ \\
\hline & 9 to 12 months & $12(8.5)$ \\
\hline & 13 to 15 months & $9(6.3)$ \\
\hline & 16 to 19 months & $2(1.4)$ \\
\hline & 20 to 23 months & $0(0)$ \\
\hline & 23 to 25 months & $0(0)$ \\
\hline & More than 25 months & $0(0)$ \\
\hline \multirow[t]{9}{*}{ Prior deployments } & 0 & $19(13.4)$ \\
\hline & 1 to 2 & $30(21.1)$ \\
\hline & 3 to 4 & $41(28.9)$ \\
\hline & 5 to 6 & $30(21.1)$ \\
\hline & 7 to 8 & $10(7.0)$ \\
\hline & 9 to 10 & $4(2.8)$ \\
\hline & 11 to 13 & $3(2.1)$ \\
\hline & 14 to 15 & $1(.7)$ \\
\hline & More than 20 & $4(2.8)$ \\
\hline \multirow[t]{6}{*}{ Years married } & Less than 1 year & $5(3.5)$ \\
\hline & 1 to 5 years & $36(25.4)$ \\
\hline & 6 to 11 years & $42(29.6)$ \\
\hline & 12 to 17 years & $31(21.8)$ \\
\hline & 18 to 23 years & $21(14.8)$ \\
\hline & More than 24 years & $7(4.9)$ \\
\hline \multirow[t]{6}{*}{ Number of children in the home } & 1 & $44(31)$ \\
\hline & 2 & $60(42.3)$ \\
\hline & 3 & $23(16.2)$ \\
\hline & 4 & $12(8.5)$ \\
\hline & 5 & $1(.7)$ \\
\hline & 6 or More & $2(1.4)$ \\
\hline \multirow[t]{7}{*}{ Family Support Groups attended } & 0 & $34(23.9)$ \\
\hline & 1 & $41(28.9)$ \\
\hline & 2 & $23(16.2)$ \\
\hline & 3 & $19(13.4)$ \\
\hline & 4 & $16(11.3)$ \\
\hline & 5 & $8(5.6)$ \\
\hline & 6 & $1(.7)$ \\
\hline \multirow[t]{8}{*}{ Communication } & 1 & $3(2.1)$ \\
\hline & 2 & $32(22.5)$ \\
\hline & 3 & $39(27.5)$ \\
\hline & 4 & $40(28.2)$ \\
\hline & 5 & $19(13.4)$ \\
\hline & 6 & $8(5.6)$ \\
\hline & 7 & $0(0)$ \\
\hline & 8 & $1(.7)$ \\
\hline \multirow[t]{2}{*}{ Religious activities } & Once a month & \\
\hline & $\begin{array}{l}\text { More than once a } \\
\text { month }\end{array}$ & $\begin{array}{l}71(50) \\
71(50)\end{array}$ \\
\hline \multirow[t]{2}{*}{ Race } & Minority & $15(10.6)$ \\
\hline & Non-Minority & $127(89.4)$ \\
\hline
\end{tabular}

Table 2 shows the mean, standard deviation, range, and alpha coefficient for FAPGAR and FAS, which measured satisfaction with family function and family adaptation. On average, partici- 
pating families reported high levels of satisfaction with interdependence and high levels of family adaptation.

Table 2: Summary of Variables Measured By Instruments

\begin{tabular}{lllll}
\multicolumn{5}{c}{ Table 2: Summary of Variables Measured By Instruments } \\
\hline $\begin{array}{l}\text { Variable } \\
\text { Instrument }\end{array}$ & $\begin{array}{l}\text { Number of } \\
\text { items }\end{array}$ & $\begin{array}{l}\text { Mean } \\
\text { (SD) }\end{array}$ & Range & $\begin{array}{l}\text { Alpha } \\
\text { Coefficient }\end{array}$ \\
\hline $\begin{array}{l}\text { Interdependence } \\
\text { Family APGAR }\end{array}$ & 5 & $16(2.61)$ & $0-20$ & .81 \\
$\begin{array}{l}\text { Family } \\
\begin{array}{l}\text { Adaptation } \\
\text { Scale }\end{array}\end{array}$ & 11 & $64(7.87)$ & $11-77$ & .86 \\
\hline
\end{tabular}

The bivariate correlation matrix of independent variables included in the multiple regression analysis with family adaptation as the criterion variable is summarized in Table 3. Military rank, length of deployment, number of prior deployments, years of marriage, and number of children in the home, participation in FSGs, communication during the deployment, participation in religious activities, interdependence, and ethnicity were the hypothesized predictor variables.

Table 3: Bivariate Correlations between Family Adaptation and the Predictor Variables

\begin{tabular}{|c|c|c|c|c|c|c|c|c|c|c|}
\hline Variable & 1 & 2 & 3 & 4 & 5 & 6 & 7 & 8 & 9 & 10 \\
\hline \multicolumn{11}{|l|}{ Adaptation } \\
\hline Rank & .08 & & & & & & & & & \\
\hline Length of deployment & .00 & .09 & & & & & & & & \\
\hline Years of marriage & -.09 & $.22 * *$ & $.26 * *$ & $.49 * *$ & & & & & & \\
\hline Number of children in the home & -.07 & -.06 & .04 & $.20 *$ & $.32 * *$ & & & & & \\
\hline Religious activities & -.03 & .14 & .13 & .10 & $.33 * *$ & $.27 *$ & & & & \\
\hline Communication & .07 & .04 & .11 & -.05 & -.02 & -.05 & .09 & & & \\
\hline Family Support Groups attended & .14 & .06 & -.15 & -.05 & .05 & -.11 & -.05 & .09 & & \\
\hline Interdependence & $.66^{* *}$ & .10 & .01 & -.04 & -.10 & -.15 & $.19^{*}$ & .05 & -.01 & \\
\hline Note. $* \mathrm{p}<.05, * * \mathrm{p}<.01$. & & & & & & & & & & \\
\hline
\end{tabular}

Of note, family adaptation was significantly correlated with one predictor variable: family satisfaction with interdependence $(r=$ $66, p<.05$ ). Thus, families with higher interdependence satisfaction scores reported higher adaptation scores. Table 3 also depicts correlations among the predictor variables. While most of the correlations among predictor variables were small to moderate, there was a significant moderate correlation between years of marriage and prior deployment. A history of prior deployments was significantly associated with longer marriages.

Analyses were conducted to evaluate multiple regression assumptions. Normality was present with all predictor variables except rank and participation in religious activities. These two variables were initially bimodal in distribution and were corrected with indicator coding for normality distribution. The predictor variable, interdependence, as measured by the FAPGAR was homoscedastic.

The effects of the predictor variables on post-deployment adaptation are displayed in Table 4 . The criterion variable, family adaptation, was regressed with each of the nine predictor variables of length of deployment, prior deployments, years married, number of children, participation in religious and FSGs, communication, race and interdependence. The nine predictor variables revealed an $\mathrm{R}^{2}$ of $.458, \mathrm{~F}((9,132)=12.41, \mathrm{p}<.001)$. An adjusted $\mathrm{R}^{2}$ was also reported to give a more conservative estimate given the sample size and the number of variables (Munro, 2001; Tabachnick \& Fidell 2007). The adjusted $\mathrm{R}^{2}$ of .421 indicated that $42 \%$ of the variability in post-deployment family adaptation was predicted by the nine variables listed in Table 4. Two of the nine predictor variables (as indicated by the $\beta$ weights and t-values) were significantly related to family adaptation. Specifically, both prior deployments and FAPGAR scores measuring interdependence significantly predicted adaptation in that more prior deployment was positively related to family adaptation. In addition, higher FAPGAR scores significantly predicted higher FAS scores. Other predictor variables, including military rank, length of deployment, years of marriage, number of children in the home, participation in religious activities, communication during deployment, and participation in FSGs, did not significantly predict post-deployment adaptation in Navy families.
Table 4: Effects of Predictor Variables on Family Adaptation

\begin{tabular}{lllll}
\hline Variables & $\mathrm{B}$ & $\mathrm{SE} \mathrm{b}$ & $\beta$ & $\mathrm{T}$ \\
\hline Constant & 31.16 & 4.007 & & 7.777 \\
Rank & 1.189 & 1.121 & .075 & 1.060 \\
Length of deployment & -.230 & .859 & -.019 & -.268 \\
Prior deployments & .693 & .322 & $.170 *$ & 2.150 \\
Years of marriage & -.873 & .548 & -.138 & -1.593 \\
Number of children in the Home & .374 & .532 & .050 & .704 \\
Religious Activities & -.050 & 1.098 & -.003 & -.046 \\
Communication & .301 & .408 & .048 & .738 \\
Family Support Groups Attended & .159 & .342 & .031 & .464 \\
Interdependence & 1.193 & .201 & $.643 * *$ & 9.644 \\
Note. $\mathrm{R}^{2}=.46$, Adjusted $\mathrm{R}^{2}=.42, * \mathrm{p}<.05, * * \mathrm{p}<.0001$ & & \\
\hline
\end{tabular}

Content analysis was used for qualitative data analysis. The categories of the RAM levels of adaptation were used to classify the data. In keeping with the RAM three levels of adaptation, the responses to the open-ended questions were coded as integrated life process, compensatory life process, and compromised life process. These responses reflected the integrity of the family system (Roy \& Andrews 1999, Fawcett 2004). According to Hanna and Roy (2001), an integrated life process or integrated adaptation levels occur when structure and function worked together to meet the needs of the family. The compensatory life process or compensatory adaptation level indicates that major coping processes were activated by the integrated life process so that the family can achieve a higher level of adaptation. A compromised life process or compromised adaptation level results from inadequate compensatory life process, which is an adaptive problem.

Qualitative question 1, "How has the reunion been for you and your family?" provided evidence for the focal stimulus of the study, data for the focal stimulus of the spouse's return, and information about family adaptation to the focal stimulus. Answers consisting of "special," "magnificent," and "good" reunions were classified as integrated adaptation levels as these terms suggested the needs of the family are being met (Hanna \& Roy 2001). Sixty percent $(n=6)$ of the spouses used these words to describe reunions. Two $(20 \%)$ spouses indicated the resumption of a "regular routine" or had "no problems adjusting." These comments were followed by statements confirming a sense of togetherness as a family in spending time together, such as "as usual everything falls right back into place." The responses were indicative of an integrated adaptation level.

"Difficult" or "slow" transitions were reported by two (20\%) spouses and were classified as compensatory adaptation level. One wife reported, "Difficult transition at times." The response indicated that the transition was difficult at times and suggested that there were also times that the transition was not difficult. This 
response was considered to be a compensatory adaptation level response as the terms indicated there were activities promoting improved adaptation in the family (Hanna \& Roy 2001). Another spouse reported a "Slow adjustment to "normal' life with dad involved again" but "Much better than previous deployments." The statement was considered to be a compensatory adaptation level response because the statement suggested that adjustment was slow but better than with previous deployments.

All spouses indicated that change occurred in the family upon return of the spouse. It was the return of the deployed spouse that was the focal stimulus that created the change in the family that required the family to respond and adapt. The spouses referred to change ranging from special and good to slow and difficult Eighty percent of the spouses reported integrated adaptation levels during the reunion. However, $20 \%$ of the spouses reported compensatory adaptation levels.

Qualitative question 2 provided the evidence for the stabilizer coping mechanism. This question asked, "What type of communication was the most important for you during the deployment and why was it important?" E-mail was the most important type of communication for $50 \%$ of the spouses. Forty percent $(n=4)$ of the spouses reported that phone calls were most important. Of the 10 spouses, one spouse reported that e-mails and letters were the most important forms of communication, and another spouse reported phone calls and e-mails were most important. E-mail was the most important form of communication for a majority of the spouses; however, one commented, "Email is so fast and it is never private." Military spouses know that electronic communication from military sources must be secure; therefore, e-mail can be reviewed to prevent the service member from sharing sensitive information that may put the military at risk, confirming the limitations of e-mail.

Participants were also asked why a particular form of communication was important, providing opportunity for the spouses to explain. The question also sought responses about the maintenance of the family through communication. Three spouses wrote that receiving e-mails from spouses was reassuring. One stated, "Getting a daily email meant so much. If the email was down or he was out somewhere without email, then those days would be long. It would make me worry sometimes if I didn't get an email within 3 days." These feelings indicated the use of the stabilizer coping process and a compensatory adaptation level (Hanna \& Roy 2001)

Two spouses found that e-mail was most important because this type of communication kept spouses updated on changes within the family and maintained connectedness. A spouse reported, "We were able to communicate almost daily and that kept us connected." Respondents were specific in acknowledging the importance of communication in the maintenance of families. These responses were examples of the stabilizer coping mechanism within RAM (Hanna \& Roy 2001). They were indicative of an integrated adaptation level as the family was being maintained.

Quick e-mail responses from deployed spouses were reported by two spouses as being important. One recalled, "The days when we numbered our envelopes to keep things orderly." The importance of quick e-mail responses, particularly with significant family matters, offered stability to the spouse at home who may have needed to make important decisions for the family. These responses indicated an integrated adaptive level.

One spouse expressed enjoyment in receiving letters because "they took time and thought." The sharing of letters documents the ongoing communication. The exchange of letters was also a stabilizer for the couple. Another spouse, also citing letters as an important form of communication, commented, "I still think 'snail mail' gives more personal communication." As with the previous spouse, the importance of the letters provides stability by sharing personal information between the couple. This was another example of an integrated adaptive level as the couple developed ongoing communication that promotes stability and integration of structure and function in the family (Hanna \& Roy 2001).
Forty percent $(n=4)$ of the spouses reported phone calls as the most important means of communication. One of the spouse's responses included phone calls, e-mails, and "snail mail." This spouse did not identify the importance of one method over the others but said, "My husband always seems to call when I needed to talk with him the most." Phone calls gave spouses the opportunity to use stabilizer coping mechanisms to maintain the family. A second spouse wrote, "Weekly phone calls to keep informed of what was going on with the kids, daily life." This spouse clearly documented the maintenance of the family and the importance of weekly phone calls reflecting an integrated adaptation level. Two spouses specifically indicated that phone calls were the most important method of communication but did not elaborate.

Overall, $50 \%$ of the spouses $(n=5)$ indicated a response that could be assessed as indicating an integrated adaptive level. Thirty percent $(n=3)$ indicated a compensatory adaptation level response by using coping processes for reassurance when hearing from spouses. Twenty percent $(n=2)$ of the spouses identified phone calls as the most effective means of communication without providing further comments or explanations as to why the phone calls were the most important to them. Brief responses such as phone calls were difficult to evaluate and considered equivocal.

The evidence of the innovator coping mechanism was assessed by asking, "What has helped you adjust to your spouse's return?" This question sought responses indicative of the innovator coping mechanism. The innovator coping mechanism involves structures and processes for change (Roy \& Andrews 1999). The majority of the spouses gave more than one response to this question. All responses were reviewed for content. Only the primary response from each spouse was used for the analysis. Time was the predominant response to this question.

Forty percent of the spouses $(n=4)$ indicated that time were required for families to adjust after the spouse returned from deployment. One spouse commented, "Remembering that time stands still for them and to give them time to adjust to our schedule. Since our life continues, we always give him about a two week 'honeymoon' phase so he can adjust back to the old routines." This family was demonstrating a compensatory adaptation level as demonstrated by understanding that time was required for the family to begin functioning as a unit during post deployment. Another responded, "More than anything, time. It just takes time." These comments indicated that the family was at the compensatory adaptation level while working to achieve a higher level of adaptation. A third spouse answered, "Taking it slow," indicating that time was needed to adjust but did not provide additional information in the response; however, this response still suggests a compensatory level of adaptation. Another spouse commented that "Just doing things together" helped the family to adapt to the return of the husband, indicating an integrated level of adaptation through the maintenance of the structure and function of the family, thus keeping it intact (Hanna \& Roy 2001).

Twenty percent of the spouses $(n=2)$ indicated that communication helped them to adapt to the return of the deployed member. One spouse indicated that sending e-mails during the deployment helped make adjustment easier. The spouse stated, "I think emailing on a regular basis helped to keep each of us informed of changes in our lives. Mostly ours at home, so there weren't many surprises around the house with our finances." This spouse's comments illustrated the use of stabilizer coping mechanism during the deployment, which resulted in an integrated adaptation level. Another spouse reported, "Open communications...we always talk things out and we never go to bed angry." This spouse was using coping mechanisms to adapt, and the spouse's comments indicated a compensatory adaptation level.

Experience with prior deployments was expressed by $10 \%$ of the spouses $(n=1)$ who stated that "prior experience with deployments" helped the family to adapt. The response reflected a need to adapt, yet it was difficult to assess the adaptation level due to the brief comment.

The family routine was also identified as helping with adaptation for $20 \%$ of the spouses $(n=2)$. One wife stated, "I honestly don't 
know. We just fall back into place." The response was brief and suggested that the family maintained its structure and function, reflecting an integrated level of adaptation. Another spouse commented, "What helps us adjust is the fact that Daddy has to fit into our routine as a family. We function the same if he is here or away. It makes the transition easier to keep business as usual. Daddy needs to adjust to us not us adjust to him being home. This helps our family to stay focused." The description given by this spouse describes the importance of structure and routine to family maintenance and post-deployment family adaptation. The comments describe stabilizer coping mechanism and not the innovator coping mechanism. This was the case that required further review and interpretation between two of the researchers. With the use of the FAS score from this participant, the researchers found that the quantitative data supported the qualitative response as evidence of stabilized coping mechanism resulting in a compensatory level of adaptation. Convergence was found to occur between the participants' qualitative and quantitative responses.

One $(10 \%)$ spouse stated, "Our love and commitment for each other always makes our adjustments easier." Given that both love and commitment are essential for a family to work as a whole to meet the needs of the family; this comment reflected an integrated adaptation level.

Forty percent $(n=4)$ of the spouses gave a response that was indicative of an integrated level of adaptation. Another $40 \%(n=4)$ of the spouses' responses indicated compensatory levels of adaptation. One (10\%) spouse's response regarding the importance of a family routine in which only the husband needed to adjust was indicative of a compromised adaptation level. Only one (10\%) spouse's response was so brief that it was difficult to assess the adaptation level.

The evidence of adaption was asked in question 4: "Now that your spouse has been home, how are things going with you and your family? Please give an example." This question allowed the spouse to identify activities or emotions that indicated family adaptation. In accordance with RAM, responses were categorized as either being at the integrated, compensatory, or compromised level of adaptation.

Sixty percent of the spouses $(n=6)$ used positive terminology to describe how things were going for the family. Phrases such as "great to have him around," "fully adjusted," and "everything is wonderful" all indicate integrated adaptation levels. Those spouses provided further comments, such as "sharing responsibilities," "help with the kids, activities, and discipline," "we work well as a team," "back to the same routine with work and social events," and "spend as much time together as possible." All of these responses indicated integrated adaptation levels because the comments demonstrated engagement in activities that allowed the family to come together as a whole.

Twenty percent of the spouses $(n=2)$ indicated difficulties with adaptation. One spouse replied, "Sometimes it is hard since you have a routine and now there is an extra person thrown in the loop but it is always a small adjustment." This spouse indicated that changes in the family structure did require the family to adjust, but the adjustment did not require a major effort on the part of the family. Initially, this family experienced a compensatory adaptation level but progressed to an integrated adaptation level. A different spouse expressed some difficulty with adjustment for the teenage children: "Things are well; however, my teenage sons do not appreciate having to answer to a disciplined taskmaster." This family had a compensatory adaptation level while working together to improve the level of adaptation.

One spouse reported lengthy adjustment, indicating that her daughter had finally adjusted to the father being home after 5 months: "It has almost been five months that he has been home and things are going pretty great now. Our daughter finally warmed up to him. She looks forward to him coming home from work. And I can leave her with him and she doesn't cry when I leave." This statement indicates that the daughter's level of adaptation evolved from compromised to integrate with time.
One spouse stated: "Things were going well. My husband is on shore duty. But he works nights and that makes spending time as a family difficult. We don't seem to have that family time we so eagerly wanted when he was gone." This family appeared to have adapted to the return of the husband and was now faced with a challenge that limited the amount of time the family spent together. This comment indicated a compensatory adaptation level because of influences on family function.

Overall, the families were able to adapt. One spouse reported a delay in adapting, but this family was eventually able to achieve adaptation with time. Seventy percent $(n=7)$ of the spouses reported that the family experienced integrated adaptation following the reunion, and $30 \%(\mathrm{n}=3)$ reported compensatory adaptation. A summary of responses to open-ended questions on the Family Adaptation Questionnaire is reported in Table 5. Content analysis utilized the RAM categories of adaption level. Selection of a purposeful sample supported the credibility of the findings.

Table 5: Responses to family adaptation questionnaire

\begin{tabular}{|c|c|}
\hline \multicolumn{2}{|c|}{ Questions and examples of responses $(\mathrm{N}=10)$} \\
\hline Question & Response \\
\hline $\begin{array}{l}\text { Question 1: How has the reunion } \\
\text { been for you and your family? }\end{array}$ & $\begin{array}{l}\text { It was so good to be a family again. } \\
\text { (Integrated) }\end{array}$ \\
\hline Please give a brief example of & The initial reunion was great. My \\
\hline how the reunion has been for & daughter took about a month to warm \\
\hline your family. & $\begin{array}{l}\text { up to him which was really hard on } \\
\text { him. (Compensatory) }\end{array}$ \\
\hline & $\begin{array}{l}\text { Difficult transition at times. (Com- } \\
\text { promised) }\end{array}$ \\
\hline
\end{tabular}

Question 2: What type of communication was the most important for you during the deployment and why?

Email! Getting a daily email meant so much. If the email was down or he was out somewhere without email, then those days would be long. (Compensatory) Weekly phone call to keep informed of what was going on with the kids, daily life. (Integrated)

Question 3: What has helped you adjust to your spouse's return?

It just takes time and communication with your partner. (Compensatory) We just fall back into place. (Integrated)

Question 4: Now that your spouse has been home, how are things going with you and your family? Please give an example.

It is hard since you have a routine and now there is an extra person thrown into the loop but it is always a small adjustment. (Compensatory) The kids are thrilled and we spend as much time together as possible. (Integrated)

\section{Discussion}

The purpose of this study was to identify variables that predict post-deployment family adaptation of Navy families. The predictor variables were selected using theoretical concepts from the RAM. The focal stimulus within the study was defined as the return of the service member. The contextual stimuli were those that could also be identified as affecting a situation (Roy \& Andrews 1999). Nine contextual stimuli served as predictor variables in a regression analysis. Of the nine predictor variables, only number of prior deployments was a significant predictor of family adaptation. Post-deployment adaptation was greatest among families with the most prior deployments. This finding contrasts with the findings of Kelley, Herzog-Simmer, and Harris (1994) who examined the effects of a long-term, military-induced separation on the level of parenting stress and family function of mothers. That study did not find a significant correlation between prior deployments and parenting stress, nor did it support prior deployment as predictive of post-deployment adaptation.

Gambardella (2008) studied the effectiveness of role exit theory as an intervention for military couples experiencing marital discord after an extended deployment. That study did not support prior 
deployments as a predictor of post-deployment adaptation while the current study did.

The stabilizer subsystem within the RAM involves system maintenance, including structure, values, and daily activities, to accomplish the purpose of the social system or family (Hanna \& Roy 2001). In the current study, the type of communication methods served as a stabilizer construct because communication contributed to the maintenance of daily activities to accomplish the purposes of the family. The number of communication methods used was not a predictor of family adaptation. Possibly, the frequency of communication is more important than the types of communication methods in terms of predicting post-deployment family adaptation. Qualitative findings also suggest that, for some families, the type of communication is important. Previously published research does not address the frequency or method of communication as predictors of post-deployment adaptation, making it a fruitful area for future exploration.

The innovator subsystem construct within the RAM reflects the "cognitive and emotional strategies for change to higher levels or potential" (Roy \& Andrews 1999 p. 48). For this study, the innovator subsystem was defined as participation in family FSG programs to prepare for post-deployment changes. Participation in FSGs did not predict post-deployment adaptation in this study. In one of the few studies that addressed how FSG attendance was associated with post-deployment adjustment, Rosen, Durand, Westhuis, and Teitelbaum (1995) focused on marital adjustment in U.S. Army spouses one year after Desert Storm. These researchers found that not attending FSGs prior to deployment predicted a poor adjustment style. In contrast, the current study found that attendance at FSGs by spouses at home during deployment was not a predictor of post-deployment adaptation. These inconsistencies suggest the need to investigate FSG participation during all phases of deployment as a predictive of post-deployment adaptation and to determine if unmeasured mediating variables influence the relationship between FSG participation and post-deployment outcomes. Along those lines, Rabb et al. (1993) recommended more structured studies to compare individual military units exposed to FSGs to units with those that were not exposed to FSGs based on anecdotal accounts of families of reservists serving during(ODS/ODS).

Other published anecdotal accounts support the importance of the return and reunion programs offered by Navy Family Service Centers. Blasure and Arnold-Mann (1992) reviewed these programs noting that program content included information about role flexibility and family communication. Qualitative findings from the current study support the importance of both.

Similarly, Black's (1993) review of the literature on military family separations during World War II, the Vietnam War, and peacetime deployments indicates that integration and adaptability were important family resources that facilitated adaptation to stress. Adaptability was identified as the most important resource for families. Although Black sought to identify resources that assisted families in adapting to stress during deployments while the current study sought to identify predictors of post-deployment family adaptation, both studies focused on adaptation of families and deployment. Addressing reintegration stress in ODS/ODS families, Peebles-Kleiger and Kleiger (1994) recommended that wartime reintegration programs include relevant wartime content and post-deployment counseling versus peacetime content and counseling. The current study supported the importance of FSGs but did not provide evidence that participation in FSGs predicted adaptation.

In the current study, interdependence, measured by the FAPGAR, was a significant predictor of family adaptation. The specific construct of interdependence in the RAM has not been measured previously in families during wartime or peacetime deployments. Other researchers investigated concepts that are similar or related to interdependence. Kelley (1994) measured support, warmth, and cohesiveness to study the impact of long-term, military-induced separations on families during ODS/ODS. She compared these concepts between families experiencing routine and war related deployments during and after the deployments. Kelley's results neither support nor refute the current study findings, although similar concepts were investigated.

Roy and Andrews (1999) identified adaptation levels to determine the range of coping for families. Adaptation levels were designated as the significant internal input and stimuli with three possible conditions of life processes of the adaptive system: integrated, compensatory, and compromised. The current study mean FAS score was suggestive of adaptation.

The investigators of the current study did not find previous studies that used the FAS to assess post-deployment adaptation in Navy families. Rather, the FAS has been used to assess families facing a variety of illnesses. The current study did not address the presence of a life-altering illness in participating Navy families. The use of the FAS with Navy families potentially expands the use of this instrument to explore family stressors independent of chronic illness.

Participation in religious activities, a contextual stimulus, was not predictive of adaptation levels in the current study. The reported statistic for this study indicated that $50 \%$ participated in religious events less than once a month during the deployment and 50\% more than once a month during the deployment. Based on these findings, the participation in religious events could be further explored as a resource for Navy families.

The qualitative findings of this study provided important insights into the post-deployment experiences of participating families. The first question asked, "How has the reunion been for you and your family?" provided data about the impact of the focal stimulus - the return of the service member spouse on family adaptation. All of the participants in the study indicated that change occurred in the family upon the return of the spouse to which the families had to adapt. The return of the service member was described by the spouses as varying from special and good to slow and difficult. Most spouses reflected integrated adaptation levels while one quarter reported compensatory adaptation levels.

One spouse reported that the daughter needed time to warm up to her father when he returned from deployment. It took her daughter about a month for her to acclimate to having the father at home. This study did not collect data about the child's behavior or life changes. Another spouse reported that the teenage sons were having problems adjusting to the father's return and strict discipline. In a review of the adverse effects of stressful life events on children's wellbeing, Pierce, Vinokur, and Buck (1998) evaluated the effects of wartime life changes on children whose mothers served in the U.S. Air Force during ODS/ODS. These investigators found that children's adjustment problems during deployment were transient and were resolved during the post-deployment period. Consistent with the current study, these authors also conceptualized the return of the spouse as a focal stimulus.

A post ODS/ODS study by Medway et al. (1995) sought to gain an understanding of factors that contributed to distress of families during wartime separations. These authors reported that mothers with lower attachment security during the deployment had children with more behavioral problems 6 months after the family was reunited. That study supported the occurrence of post-deployment child adjustment problems reported in the current study of Navy families. The conceptualization of the return of the spouse as a focal stimulus was also supported by Medway et al.

The stabilizer coping process involves system maintenance and daily activities to accomplish the purpose of the social system of the family (Hanna \& Roy 2001). Qualitative question 2 gave insight into communication and the stabilizer coping mechanism, which assisted in maintaining daily family functioning. This question asked, "What type of communication was most important for you during the deployment and why was it important?" This question was asked to assess activities, such as communication, in maintaining the family during deployment. E-mail was the most important method of communication for the sample. The next most important method of communication was phone calls.

The current study and the study by Gambardella (2008) are the only studies known to report on communication during deploy- 
ment and post-deployment adaptation. Gambardella's study specifically identified satisfaction with communication during the deployment as affecting post deployment while the current study found that methods of communication during deployment were not predictive of post-deployment adaptation. The two studies investigated different aspects of communication; however, both studies demonstrated the importance of communication during and after deployment.

The innovator subsystems construct "involves cognitive and emotional strategies for change to higher levels or potential" (Roy \& Andrews 1999 p. 48). Responses from spouses regarding those resources or activities they considered cognitive or emotional strategies helped them to adjust to the return of the spouse. Qualitative question 3 asked respondents the following: "What has helped you adjust to your spouse's return?" This question was designed to identify strategies that helped families adjust to the return of the spouse. Most spouses gave more than one response to this question, time being the most frequent response. Forty percent of the spouses in this study reported that time helped in adapting to the spouse's return. Similarly, in a quantitative study by Faber, Willerton, Clymer, MacDermid, and Weiss (2008) addressing the struggles of post-deployment, participants reported needing time to adjust to having the spouse home when it came to communicating daily activities, checking on each other's preferences, and making joint decisions. Spouses in the current study reported giving the husband and family time to adapt during the postdeployment period. Both studies supported the importance of allowing time for the family to readjust during post deployment. Qualitative question 4 asked, "Now that your spouse has been home, how are things going with you and your family?" and "Please give an example." Spouses answered this question with phrases such as "great to have him around," "fully adjusted," and "everything is wonderful." All of these statements indicated integrated adaptation levels. The spouses provided the following further comments: "sharing responsibilities," "help with the kids, activities, and discipline," "we work well as a team," "back to the same routine with work and social events," and "spend as much time together as possible." All of these responses indicated the families had integrated adaptation levels. Seventy percent of the spouses' responses indicated an integrated adaptation level, with a third of the responses indicating a compensatory adaptation level. Using a qualitative study design, Faber et al. (2008) studied postdeployment adaptation of a sample of 34 military families following a deployment in Iraq. The findings of that study also reflected the importance of time in achieving adaptation. As with the qualitative findings of the current study, qualitative findings in the Faber et al. study emphasized the significance of spending time together as a family and allowing time for adaptation.

An event that seemed to help with how families adjusted was the return of the reservists to civilian jobs. This event helped to establish a more familiar routine for the family. Both reservists and active duty members of the service had many of the same issues with deployment, but one difference between reservists and service members was that reservists could return to civilian jobs. With mixed methods findings, there were two predictor variables and a criterion variable that were considered to have quantitative and qualitative components. The hypothesized predictors were participation in FSGs and methods of communications. The criterion variable was family adaptation. Neither the quantitative nor qualitative data showed that participation in FSGs was a predictor of adaptation. Collectively, these results suggested that participation in FSGs may not advance adaptation in Navy families.

The criterion variable for this study was family adaptation. Results of quantitative and qualitative findings predicted post-deployment family adaptation in this research. The mean score of the FAS was high, suggesting high adaptation. An integrated level of adaptation was also reflected in the qualitative responses. Seven out of 10 respondents who participated in the qualitative portion of the study reported an integrated level of adaptation.

This current study adds important insights about the influences of military deployment on family adaptation, as past studies have not examined prediction or this important outcome. There are, however, several methodological limitations that should be addressed in future studies. Reliable and valid data collection via the Internet requires that respondents have the ability to access the websites and Web-based surveys. As with all written surveys, participants must be able to read and comprehend the survey placed on the website (Strickland et al. 2003). Participants in an online survey likely had access to a computer and the ability to use a computer. Computer owners and users are generally more affluent and educated than the general population (Strickland et al. 2003), thus creating potential bias in the sample. In addition, this study sample may include experienced spouses, which could explain why $24 \%$ of the sample did not attend any FSGs as they may have been familiar with post-deployment programs and activities. Having prior deployment experiences may have also contributed to high FAS scores. Moreover, few of the study participants were members of ethnic minority groups thus limiting the data collected from those groups. Despite these limitations, the findings regarding the importance of communication and time in the postdeployment adaptation of families are similar to the findings of other quantitative and qualitative studies focused on military family adjustment to deployment.

To address these limitations, future studies should include strategies to assure that respondents are military families from diverse racial/ethnic groups that respond only once. Other family or military related demographics should be considered as contextual stimuli, such as frequency of communication, frequency of participation in FSGs, the age of children in the home, and educational level of the spouse as potential predictor variables. The inclusion of data from the military member, couple or entire family is also recommended.

The RAM, in part, explained the hypothesized relationships among the predictor variables and family adaptation. Prior deployment was a significant predictor of family adaptation as hypothesized by the model. Interdependence, as an adaptive mode, was also confirmed as a predictor variable of family adaptation. The qualitative data confirmed that communication methods, a contextual stimulus, were associated with post deployment family adaptation. The strongest predictor variable for family adaptation was interdependence as measured by the FAPGAR. Screening families with this brief instrument may be beneficial to military healthcare providers, including mental healthcare providers to assess family adaptation levels prior to, during, and after military deployment.

The RAM provides directions for clinical practice as findings suggest that the model may help to inform the care of Navy families. Interdependence was shown to predict post-deployment adaptation, suggesting that assessment of family interdependence is relevant for clinical assessment. Each study concept described in RAM could assist nurses to better recognize family issues and concerns and influence care of families. Knowledge of predictors of family adaptation could result in appropriate referrals to assist families to adapt while additional research could improve the health care of military families.

While nurse educators have incorporated diversity into the curriculum, military families should be included as representing diversity among families. Topics such as the impact of war and peacetime deployments; phases of deployment; and the assessment, planning, and assessment of military families should be included.

\section{Conclusion}

Military families will continue to experience war and peacetime deployments. They will need support to enhance family adaptation throughout all phases of deployment. Developing effective interventions to meet the needs of military families will require additional research to assure that interventions effectively address the needs of the diverse populations that comprise these families. Replicating the current study with a larger sample size, over- 
sampling of minority families, and the inclusion of other armed services branches would assist in identifying family related adaptation issues. Studies of post-deployment family adaptation involving a service member with a war related physical or mental health disorder needing rehabilitation services is also recommended. Post-deployment family adaptation studies should also be conducted with families of reservists who deployed with a unit and without a unit as an individually augmented reservist. Consideration should also be given to sampling young wives or wives new to the demands of military service. This group may have unique challenges adapting to the military way of life that could be addressed by FSGs or other family services.

\section{Acknowledgments}

The authors would like to thank Dr. Mona N. Wicks, Professor, University of Tennessee health Science Center College of Nursing, for her thoughtful review of several drafts of this study, discussions with the authors, and valuable comments. Dr. Michelle Kelley, Professor, Old Dominion University provided expert advice on military family research, Dr. Jamie Forst contributed statistical support, and Ms. Sarah Spangler provided editorial advice.

\section{References}

[1] Adams GA, Durand DB, Burrell L, Teitelbaum, JM, Pehrson, KL, \& Hawkins, JP (2005) Direct and indirect effects of Operation Tempo on outcomes for soldiers and spouses. Military Psychology, 17 (3), 229246. doi: $10.1207 / \mathrm{s} 15327876 \mathrm{mp} 17036$

[2] Antonovsky a \& Sourani T (1988) Family sense of coherence and family adaptation. Journal of Marriage and the Family, 50, 79-92 doi: $10.2307 / 352429$

[3] Black WG (1993) Military-induced family separation: A stress reduction intervention. Social Work, 38(3), 273-280 doi:10.1093/sw/38.3.273

[4] Blasure KR \& Arnold-Mann J (1992) Return and reunion: A psychoeducational program aboard U.S. Navy ships. Family Relations, 41(2), 178-185. doi: 10.2307/584830

[5] Castro CA \& Adler AB (2005) Preface to the special issue [Abstract]. Military Psychology, 17 (3), 131-136. doi 10.1207/s15327876mp1703_1.

[6] Chamberlain CC. (2002) Object relations theory and family dynamics in schizophrenic patients, non-psychotic patients, and control: An empirical study (Doctoral dissertation, University of Detroit Mercy). Retrieved from Dissertation Abstracts International (UMI No. 3062891).

[7] Faber AJ, Willerton E, Clymer SR, MacDermid SM \& Weiss HM (2008) Ambiguous absence, ambiguous presence: A qualitative study of military reserve families in wartime. Journal of Family Psychology, 22(2), 222-230. doi:10.1037/0893-3200.22.2.222

[8] Fawcett J (2004) Contemporary nursing knowledge: Analysis and evaluation of nursing models and theories (2nd ed.). F.A. Davis, Philadelphia PA.

[9] Gambardella LC (2008) Role-exit theory and marital discord following extended military deployment. Perspectives in Psychiatric Care, 44(3), 169-174. doi: 10.1111/j.1744-6163.2008.00171.x

[10]Grotevant HD \& Carlson C (1989) Family assessment: A guide to methods and measures. The Guilford Press, New York NY.

[11]Hanna DR \& Roy C (2001) Roy adaptation model and perspectives on the family. Nursing Science Quarterly 14(1), 10-13. doi 10.1177/08943180122108148.

[12]Hill R (1949) Families under stress: Adjustment to the crises of war separation and reunion. Harper \& Brothers, New York NY

[13]Huebner AJ \& Mancini JA (2008) Supporting youth during parental deployment: Strategies for professionals and families. The Prevention Researcher, 15 (Suppl.), 10-13.

[14]Kelley ML (1994) the effect of military-induced separation on family factors and child behavior. American Journal of Orthopsychiatry, 64(1), 103-111. doi: 10.1037/h0079499.

[15]Kelley ML, Herzog-Simmer P \& Harris MA (1994) Effects of military-induced separation on the parenting stress and family functioning of deploying mothers. Military Psychology 6(2), 125-138. doi: $10.1207 / \mathrm{s} 15327876 \mathrm{mp} 0602 \_4$.

[16]Knox J \& Price DH (1999) Total force and the new American military family: Implications for social work practice. Families in Society: The
Journal of Contemporary Human Services, 80 (2), 128-136. doi: 10.1606/1044-3894.655.

[17] McCoy MA (2004) Family sense of coherence and perceptions of social support as mediators of adaptation to coronary artery bypass surgery. (Doctoral dissertation, Michigan State University). Retrieved from Dissertation Abstracts International (UMI No.3129518).

[18]Medway FJ, Davis KE, Cafferty TP, Chappell KD \& O'Hearn RE (1995) Family disruption and adult attachment correlates of spouse and child reactions to separation and reunion due to ODS. Journal of Social and Clinical Psychology, 14(2), 97-118. doi: 10.1521/jscp.1995.14.2.97.

[19]Munro BH (2001) Statistical methods for health care research $\left(^{\text {th }}\right.$ ed). Lippincott, Williams, and Wilkins, Philadelphia PA

[20]Newby NM (1996) the reliability, construct, and discriminate validity of the Family Sense of Coherence Questionnaire. (Doctoral dissertation, St. Louis University). Retrieved from Dissertation Abstracts International (UMI No. 9718145).

[21]Peebles-Kleiger MJ \& Kleiger JH (1994) Re-integration stress for Desert Storm families: Wartime deployments and family trauma. Journal of Traumatic Stress, 7(2), 173-194. doi 10.1002/jts.2490070203

[22]Pierce P, Vinokur, AD \& Buck CL (1998) Effects of war-induced maternal separation and children's adjustment during the Gulf War and two years later. Journal of Applied Social Psychology, 28(14), 1286-1311. doi: 10.1111/j.1559-1816.1998.tb01677.x

[23] Rabb DD, Baumer RJ \& Weisler NA (1993) Counseling Army reservists and their families during Operation Desert Storm. Community Mental Health Journal, 12(5), 441-447. doi: 10.1007/BF00754412

[24]Rosen LN, Durand D, Westhuis DJ \& Teitelbaum JM (1995) marital adjustment of Army spouses one year after Operation Desert Storm. Journal of Applied Social Psychology, 25(8), 677-692. doi:10.1111/j.1559-1816.1995.tb01768.x

[25] Roy C (2009) The Roy adaptation model ( $3^{\text {rd }}$ Ed.). Pearson Education, Upper Saddle River NJ.

[26]Roy C \& Andrews H (1999) The Roy adaptation model ( $2^{\text {nd }}$ Ed.). Appleton \& Lange, Upper Saddle River NJ.

[27]Sawin KJ, Harrigan MP \& Woog, P (1995) Measures or family functioning for research and practice. Springer, New York, NY.

[28]Smilkstein G, Ashworth C \& Montano, D (1982) Validity and reliability of family APGAR as a test of family function. Validity and reliability of family APGAR as a test of family function (2), 303-311.

[29]Speziale HJS \& Carpenter DR (2007) Qualitative research in nursing: Advancing the humanistic imperative $\left(4^{\text {th }} \mathrm{ed}\right)$. Lippincott, Williams, and Wilkins, Philadelphia, PA.

[30]St. Laurent JA (2004) Observations on recent National Guard use in overseas and homeland Missions and future challenges (GAO Publication No. 04-670T, pp.1-27). Washington, DC: U.S. General Accounting Office.

[31] Strickland OL, Moloney MF, Dietrich AS, Myerburg S, Cotsonis GA \& Johnson RV (2003) Measurement issues related to data collection on the World Wide Web. Advances in Nursing Science, 26(4), 246256.

[32]Survey Monkey (2007) Help center. Retrieved from http://www.surveymonkey.com/HelpCenter/AnswerPop.aspx?HelpID -67 .

[33]U.S. Government Accountability Office (2009) Preliminary findings on VA's provision of health care services to women veterans. Retrieved from http://www.gao.gov/products/GAO-09-884T on April 2, 2014.

[34]U.S. Government Accountability Office (2011) Homeless women veterans: Actions needed to ensure safe and appropriate housing. $\mathrm{Re}-$ trieved from http://www.gao.gov/products/GAO-12-182 on April 2, 2014 